\author{
다중벽 탄소나노튜브를 이용한 계면제어가 \\ $\mathrm{TiO}_{2}$ 나노복합체의 열전특성에 미치는 영향 \\ 남우현 ${ }^{1}$. 임영수 ${ }^{2, *}$ \\ 1한국세라믹기술원 에너지환경소재본부 \\ 2부경대학교 신소재시스템공학과
}

\title{
Effect of Interface Control Using Multiwalled Carbon Nanotubes on the Thermoelectric Properties of $\mathrm{TiO}_{2}$ Nanocomposites
}

\author{
Woo Hyun Nam ${ }^{1}$ and Young Soo $\mathrm{Lim}^{2, *}$ \\ ${ }^{1}$ Energy and Environmetal Division, Korea Insitutute of Ceramic Engineering and Technology, Jinju 52851, Republic of Korea \\ ${ }^{2}$ Department of Materials System Engineering, Pukyong National University, Busan 48547, Republic of Korea
}

\begin{abstract}
We report the effect of interface control using multiwalled carbon nanotubes (MWCNT) on thermoelectric properties of $\mathrm{TiO}_{2}$. By consolidating $\mathrm{TiO}_{2}$ nanoparticles with $\mathrm{MWCNT}(0.5,1,2,4$, and $8 \mathrm{wt} \%)$ using spark plasma sintering, we prepared interface-controlled $\mathrm{TiO}_{2}$-MWCNT nanocomposites, where $\mathrm{TiO}_{2}$ grains were surrounded with a MWCNT network. Simultaneous control of charge and thermal transport was successfully achieved by interface control using MWCNTs. The electrical conductivity increased monotonically as the MWCNT content was increased. As determined in our previous report, the charge transport mechanism in the nanocomposites is based on percolation and hopping models. The formation of new interfaces at the grain boundaries using the MWCNT network led to additional phonon scattering in the nanocomposites, and the thermal conductivities decreased monotonically with increasing MWCNT content. However, the incorporation of the MWCNT did not lead to a significant increase in power factor due to a reduction in the Seebeck coefficient. Consequently, the highest ZT value of $4.6 \times 10^{-3}$ was obtained from the TiO2-0.5 wt\% MWCNT nanocomposite at $1073 \mathrm{~K}$. Our results introduce a strategy for the independent control of electron and phonon transport based on interface control using carbon nanomaterials in hybrid thermoelectric materials.
\end{abstract}

(Received May 8, 2018; Accepted May 23, 2018)

Keywords: thermoelectric, $\mathrm{TiO}_{2}$, carbon nanotube, interface control

\section{1. 서 론}

최근 화석연료의 대대적인 사용으로 인해 환경오염 문제 가 크게 대두됨에 따라, 이를 해결하기 위해 신재생에너지 분야에 대한 연구가 전 세계적으로 활발하게 이루어지고 있다 [1-4]. 그중에서도 열전변환 기술은 폐열을 재활용하 여 전기에너지를 생산할 수 있을뿐더러 고신뢰성무소음.탄 소 발생 저감 등의 특성이 있기 때문에 지구 온난화 방지 및 신재생에너지 개발에 대한 시대적 요구를 충족할 수 있

*Corresponding Author: Young Soo Lim [Tel: +82-51-629-6384, E-mail: yslim@pknu.ac.kr] Copyright (C) The Korean Institute of Metals and Materials
는 가장 적합한 기술이라 할 수 있다 [5-7]. 이러한 특성 을 가지는 열전재료의 성능은 제벡 계수, 전기전도도, 열전 도도에 의해 결정되고, 열전성능지수 (figure of merit, $Z T), Z T=S^{2} \sigma T \kappa^{-1}$ 로 표현된다. 여기서 $S$ 는 제벡 계수 $\left(\mathrm{V} \mathrm{K}^{-1}\right)$, $\sigma$ 는 전기전도도 $\left(\mathrm{S} \mathrm{cm}^{-1}\right), \kappa$ 는 열전도도 $\left(\mathrm{W} \mathrm{m}^{-1} \mathrm{~K}^{-1}\right)$, 그 리고 $T$ 는 절대온도 $(\mathrm{K})$ 를 나타낸다. 하지만 열전재료는 전 기전도도가 증가하면, 열전도도가 함께 증가하고, 제벡 계 수가 감소하는 상호 의존적인 관계를 가지고 있어서 열전 성능지수의 개선에 어려움이 있었다. 따라서 열전재료의 성 능을 향상시키기 위해서는 전기전도도와 제벡 계수, 열전 도도를 동시에 복합적으로 제어하는 기술이 필요하다.

한편, 탄소나노물질 (carbon nanomaterials)은 그래핀 
(graphene), 탄소나노튜브 (carbon nanotube), 풀러렌 (fullerene) 등을 포함하는 대표적인 나노물질로서, 기존 소재에서는 관찰할 수 없었던 특이한 구조적 특성으로 인 해 구현되는 여러 가지의 우수한 특성을 가진다 [8,9]. 이 러한 점을 기반으로 탄소나노물질은 다양한 분야에서 널리 이용되고 있으며, 특히 나노복합소자 제조에 필수적인 빌 딩 블록 (building block)으로의 활용도가 높아지면서 응용 연구도 활발히 이루어지고 있다 [10,11]. 탄소나노물질을 다른 물질과 복합화를 할 경우 표면 개질 효과를 통해 전 하 전도 특성이 개선되기 때문에 광촉매 [12], 투명 전도 막 [13], 센서 [14-16], 에너지 저장체 [17-19] 등의 분야 에서 시너지 효과를 기대할 수 있다. 우리 연구 그룹에서 는 이러한 점에 기인하여 탄소나노물질을 열전소재에 접목 하는 연구를 진행해왔다 [20,21]. 탄소나노물질을 열전소재 분말에 코팅하거나 분산시켜 복합 분말을 제작한 후 이를 소결하여 복합체를 제작할 경우, 계면 제어 효과를 통해 전기전도도의 증진과 동시에 결정립계에 존재하는 탄소나 노물질에서 일어나는 포논 산란을 통해 열전도도가 감소하 게 되고 이를 통한 전자와 포논의 이동의 독립적인 제어를 통해 열전성능지수 향상의 가능성을 보고하였다 [22-24].

우리 그룹은 선행 연구를 통해 다중벽 탄소나노튜브 (MWCNT, miltiwalled carbon nanotube)를 이용하여 계면 이 제어된 $\mathrm{TiO}_{2}$ 나노복합체의 전하 전송 특성에 대해 보 고한 바 있다 [25]. MWCNT를 효과적으로 분산시키기 위 해 볼 밀링 방법을 이용하여 $\mathrm{TiO}_{2}-\mathrm{MWCNT}$ 복합분말을 제작하였으며, 이 복합분말을 방전 플라즈마 소결법을 이 용하여 최종적으로 $\mathrm{TiO}_{2}-\mathrm{MWCNT}$ 나노복합체를 제작하였 다. $\mathrm{TiO}_{2}-\mathrm{MWCNT}$ 나노복합체에서의 전자 전도는 percolation 모델과 3-dimensional variable-range hopping (3D VRH) 모델을 통해 전도되는 것을 밝혀내었다 [25]. 본 연구에서는 $\mathrm{MWCNT}$ 를 이용한 $\mathrm{TiO}_{2}$ 나노복합체의 계 면제어가 열전특성에 미치는 영향에 대해서 살펴보았다. 대 표적인 산화물계 재료인 $\mathrm{TiO}_{2}$ 는 불순물을 첨가하여 전기 전도도를 증가시킬 수는 있지만, 물질 자체가 가지고 있는 높은 열전도도로 인해 높은 열전성능지수를 확보하는데 있 어 큰 장애가 되고 있다. MWCNT 함량 변화에 대한 효 과를 알아보기 위해 $0.5 \sim 8 \mathrm{wt} \%$ 로 함량을 조절하였으며, 미 세구조 분석을 통해 MWCNT가 나노복합체의 결정립계에 응집 현상 없이 잘 분산된 것을 확인하였다. MWCNT를 이용한 계면 제어를 통해 나노복합체의 전기전도도의 상승 과 열전도도의 감소 효과를 동시에 구현할 수 있었으나, 캐리어 농도의 증가로 인한 제벡 계수의 급격한 감소로 인 해 열전성능지수는 MWCNT 함량이 증가함에 따라 감소
하였다. 하지만 본 연구를 통해 탄소나노물질을 이용한 계 면 제어가 재료 내의 전자와 포논의 이동을 독립적으로 제 어할 수 있다는 점과 MWCNT의 양을 적절히 조절할 경 우 계면 제어를 하지 않은 물질에 비해 높은 열전성능지수 를 얻을 수 있다는 점이 확인되었다. 이를 통해 탄소나노 물질을 이용한 계면 제어가 다른 열전소재의 열전성능 향 상에도 폭넓게 활용될 것으로 기대한다.

\section{2. 실험 방법}

$\mathrm{TiO}_{2}$-MWCNT 복합분말을 합성하기 위해 $\mathrm{TiO}_{2}$ 나노입 자 (P25, Degussa)와 MWCNT (carbon $>95 \%$, Sigma Aldrich)를 출발 원료로 사용하였다. 우선, $\mathrm{MWCNT}$ 를 $N, N$-dimethylformamide (DMF, $\mathrm{C}_{3} \mathrm{H}_{7} \mathrm{NO}, \mathrm{Sigma}$ Aldrich)에 분산시키기 위해 2시간 동안 초음파 처리를 한 후, $\mathrm{TiO}_{2}$ 나노입자를 첨가하여 20시간 동안 볼 밀링을 실 시하였다. 그 후 혼합물을 $373 \mathrm{~K}$ 의 온도로 24 시간 동안 진공 오븐에서 건조시켰다. MWCNT를 이용한 계면제어의 효과가 열전특성에 미치는 영향에 대해 알아보기 위해 복 합분말 내의 MWCNT 함량을 $0.5,1,2,4,8 \mathrm{wt} \%$ 로 조 절하였다. 이와 같은 방법으로 합성한 $\mathrm{TiO}_{2}-\mathrm{MWCNT}$ 복합 분말을 방전 플라즈마 소결법을 이용하여 $1173 \mathrm{~K}$ 에서 50 $\mathrm{MPa}$ 의 압력으로 5 분 동안 소결하여 최종적으로 $\mathrm{TiO}_{2}$ MWCNT 나노복합체를 합성하였다.

소결체의 밀도는 아르키메데스 (Archimedes)법으로 측정 하였으며, 모든 소결체는 $90 \%$ 이상의 상대밀도를 보였다. 소결체의 미세구조 특성은 주사전자현미경 (SEM, JSM$6700, \mathrm{JEOL}$ )과 투과전자현미경 (TEM, JEM-2010, JEOL) 을 이용하여 분석하였고, 전기전도도와 제벡 계수는 4탐침 법 (4 point probe method, TEP 1000, Seepel Co., $\mathrm{Ltd}$ )을 사용하여 상온에서 $1073 \mathrm{~K}$ 까지 측정하였으며, 열전 도도는 레이저 섬광법 (laser flash, LFA, DLF-1300, TA Instruments)을 활용하여 측정하였다.

\section{3. 결과 및 고찰}

그림 1(a)는 출발 원료로 사용한 MWCNT를 나타낸 주 사전자현미경 상을 보여준다. MWCNT의 직경은 $10 \mathrm{~nm}$ 정도이며 길이는 수 $\mu \mathrm{m}$ 정도이다. 그림 $1(\mathrm{~b})-(\mathrm{f})$ 는 $\mathrm{TiO}_{2}$ $0.5 \sim 8 \mathrm{wt} \% \mathrm{MWCNT}$ 나노복합체의 파단면을 보여주는 주 사전자현미경 상이다.

나노복합체의 평균 결정립 크기는 $300 \mathrm{~nm}$ 정도로 관찰 되었으며, MWCNT 함량 변화에 따라서 미세구조가 변하 

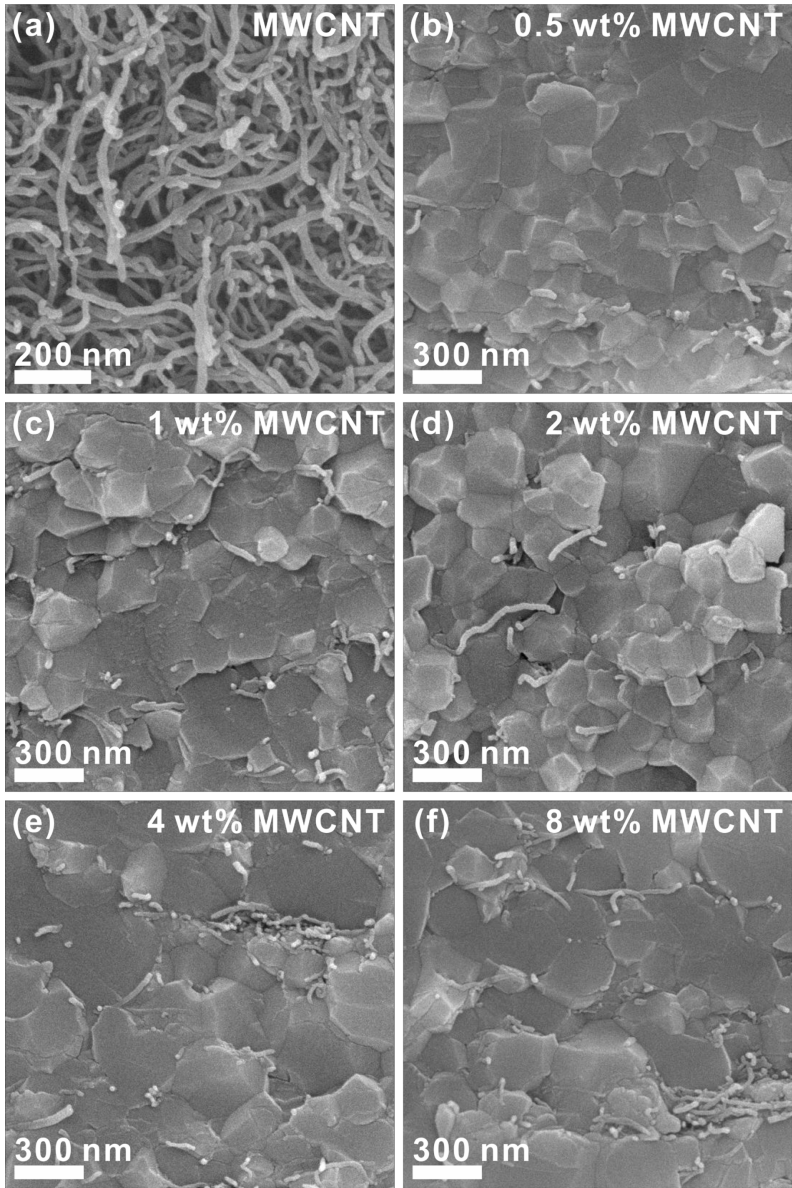

Fig. 1. SEM micrographs of (a) as-received MWCNT and (b)-(f) fractured surfaces of $\mathrm{TiO}_{2}$-MWCNT nanocomposites with $0.5,1,2$, 4 and $8 \mathrm{wt} \%$ of MWCNT, respectively.
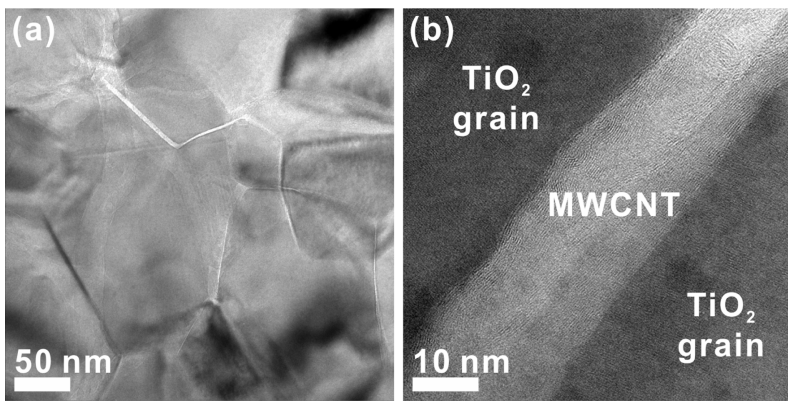

Fig. 2. Bright-field TEM and HRTEM micrographs of $\mathrm{TiO}_{2}-8 \mathrm{wt} \%$ MWCNT nanocomposite.

는 현상은 발견되지 않았다. 모든 나노복합체에서 MWCNT가 크게 응집되어 있는 현상은 관찰되지 않았으 며, 그림 2에 나타낸 투과전자현미경 상을 통해 MWCNT 가 결정립계에 고르게 분포하고 있음을 알 수 있다.

그림 $3(\mathrm{a})$ 는 $\mathrm{TiO}_{2}-\mathrm{MWCNT}$ 나노복합체의 온도에 따른
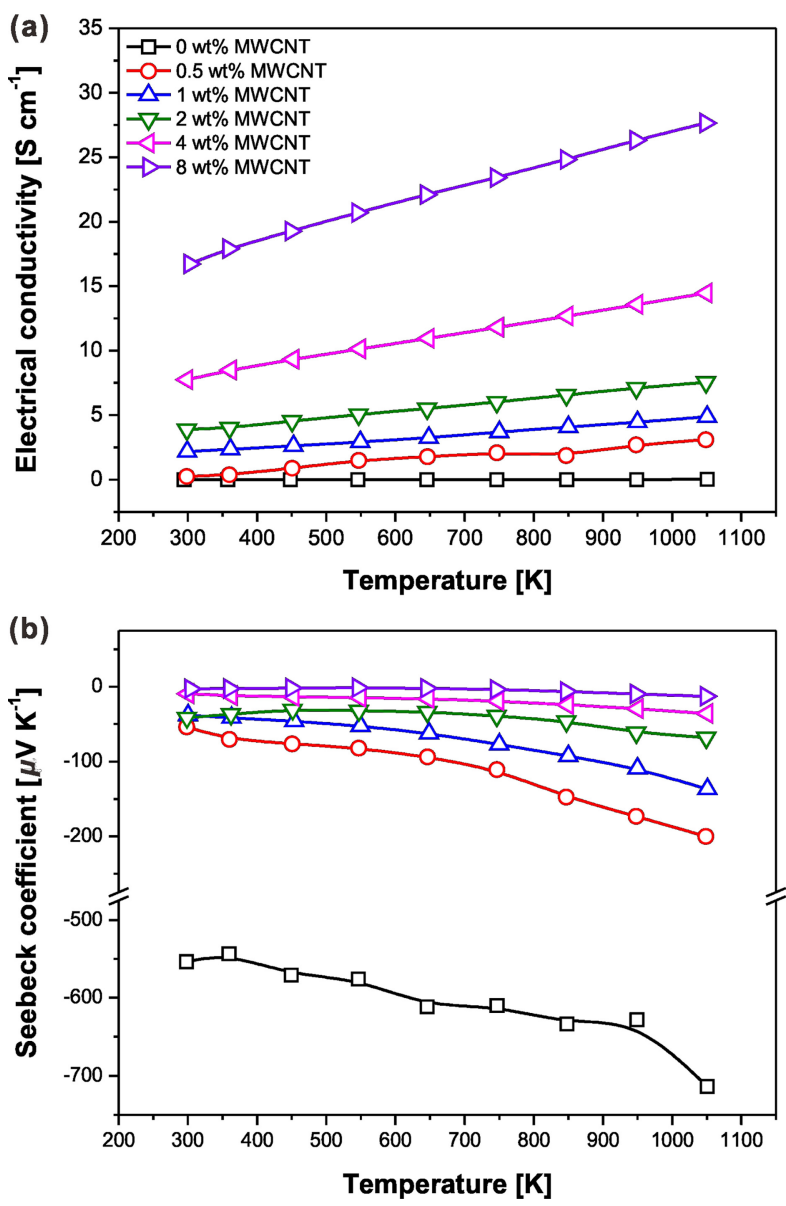

Fig. 3. Temperature dependent (a) electrical conductivities and (b) Seebeck coefficients of $\mathrm{TiO}_{2}$-MWCNT nanocomposites $[25,26]$.

전기전도도의 변화를 나타낸다. 모든 나노복합체의 전기전 도도는 온도에 따라서 증가하는 반도체 전도를 보인다.

$\mathrm{TiO}_{2}$-MWCNT 나노복합체에서의 전하 전도 메커니즘은 percolation 모델과 3D VRH 모델을 동시에 따르는 것으 로 선행 연구를 통해서 밝혀내었다 [25]. 전하 전도 메커 니즘이 percolation 모델을 따른다는 것은 MWCNT가 $\mathrm{TiO}_{2}$ matrix 내에서 네트워크를 잘 형성하고 있음을 의미 하고 [27], 3D VRH 모델을 통해서 다른 MWCNT 네트 워크 간의 전하 이동이 가능하다는 것을 의미한다 [28]. 따라서, MWCNT 함량이 증가할수록 효과적인 네트워크의 형성이 가능해짐에 따라 percolation 전도에 필요한 임계값 (percolation threshold)이 줄어들게 되고 hopping 전도에 필요한 활성화 에너지가 줄어들게 되어 그림 3(a)처럼 전 기전도도가 증가하는 경향을 보인다.

그림 3(b)는 $\mathrm{TiO}_{2}$-MWCNT 나노복합체의 온도에 따른 제벡 계수를 나타낸다. 그림 4 에 나타낸 $\mathrm{TiO}_{2}$ 와 MWCNT 


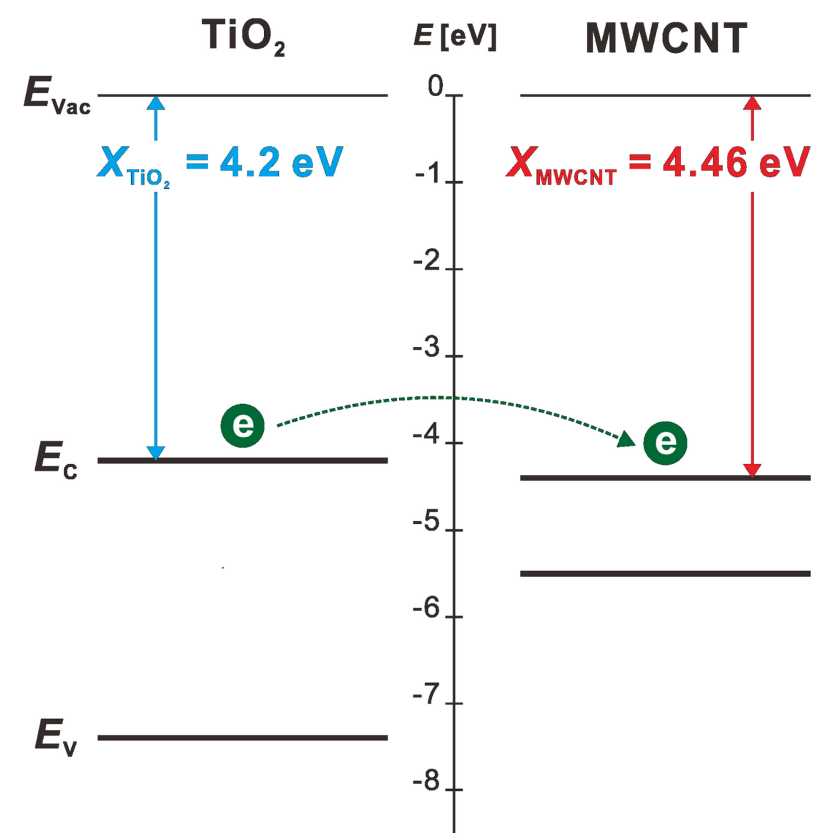

Fig. 4. A schematic band alignment of $\mathrm{TiO}_{2}-\mathrm{MWCNT}$ nanocomposites $\left(\chi_{\mathrm{TiO} 2}\right.$ : electron affinity of $\mathrm{TiO}_{2}, \chi_{\mathrm{MWCNT}}$ : electron affinity of MWCNT, $E_{\mathrm{Vac}}$ : vacuum level, $E_{\mathrm{C}}$ : conduction band, and $E_{\mathrm{V}}$ : valence band).

의 band alignment 모식도를 보면 $\mathrm{TiO}_{2}$ 결정립의 가전자 대로부터 전도대로 천이된 전자는 $\mathrm{TiO}_{2}$ 와 $\mathrm{MWCNT}$ 의 전도 대 위치 차이에 의해 MWCNT로 전이하게 된다 [29,30].

따라서 $\mathrm{TiO}_{2}$ 입자 내부에서 전자 생성이 이루어지기 때 문에 모든 나노복합체의 제벡 계수는 음의 값을 가지게 된 다. 제벡 계수는 Pisarenko 관계에 의해 캐리어 농도에 반 비례하는 관계를 가지는데, 이를 식 (1)에 나타내었다.

$$
S=\frac{8 \pi^{2} k_{B} T}{3 q h^{2}} m_{d}^{*}\left(\frac{\pi}{3 n}\right)^{2 / 3},
$$

여기서 $k_{\mathrm{B}}$ 는 볼츠만 상수, $q$ 는 전하량, $h$ 는 플랑크 상 수, $m_{\mathrm{d}}{ }^{*}$ 는 상태 밀도 유효 질량, 그리고 $n$ 은 캐리어 농도 를 나타낸다. 그림 3(b)에서와 같이 MWCNT 함량 증가에 따라 나노복합체의 제벡 계수가 현저히 감소하는데, 이는 MWCNT 함량이 증가할수록 더 효과적인 네트워크가 형 성되기 때문에 전자의 농도가 증가하였기 때문이다.

그림 5는 나노복합체의 온도변화에 따른 출력인자 (power factor)를 나타낸 것이다. 출력인자는 제벡 계수의 제곱과 전기전도도의 곱으로 표현되는데 $\left(S^{2} \sigma\right)$, $\mathrm{MWCNT}$ 함량이 증가할수록 전기전도도가 증가함에도 불구하고 제 벡 계수의 감소 효과가 더 크게 작용하기 때문에 출력인자 는 감소하는 경향을 나타내게 된다.

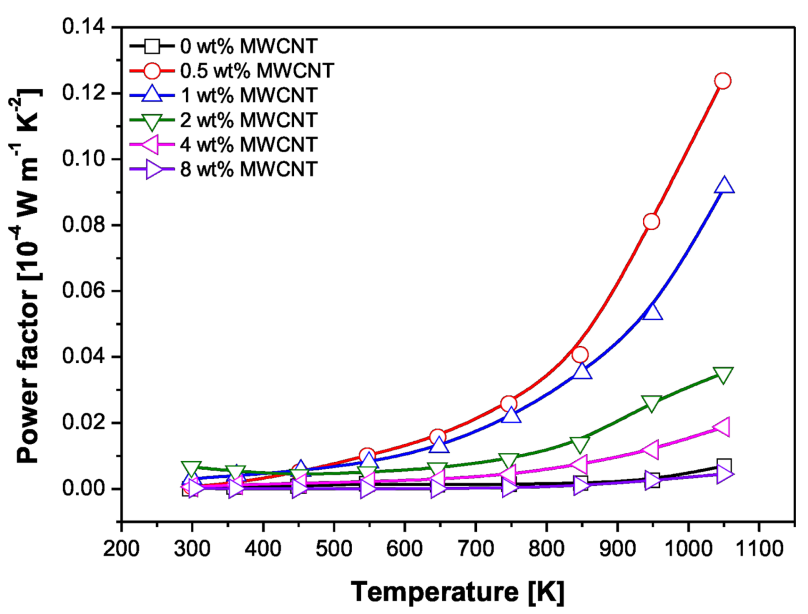

Fig. 5. Temperature dependent power factors of $\mathrm{TiO}_{2}-\mathrm{MWCNT}$ nanocomposites.
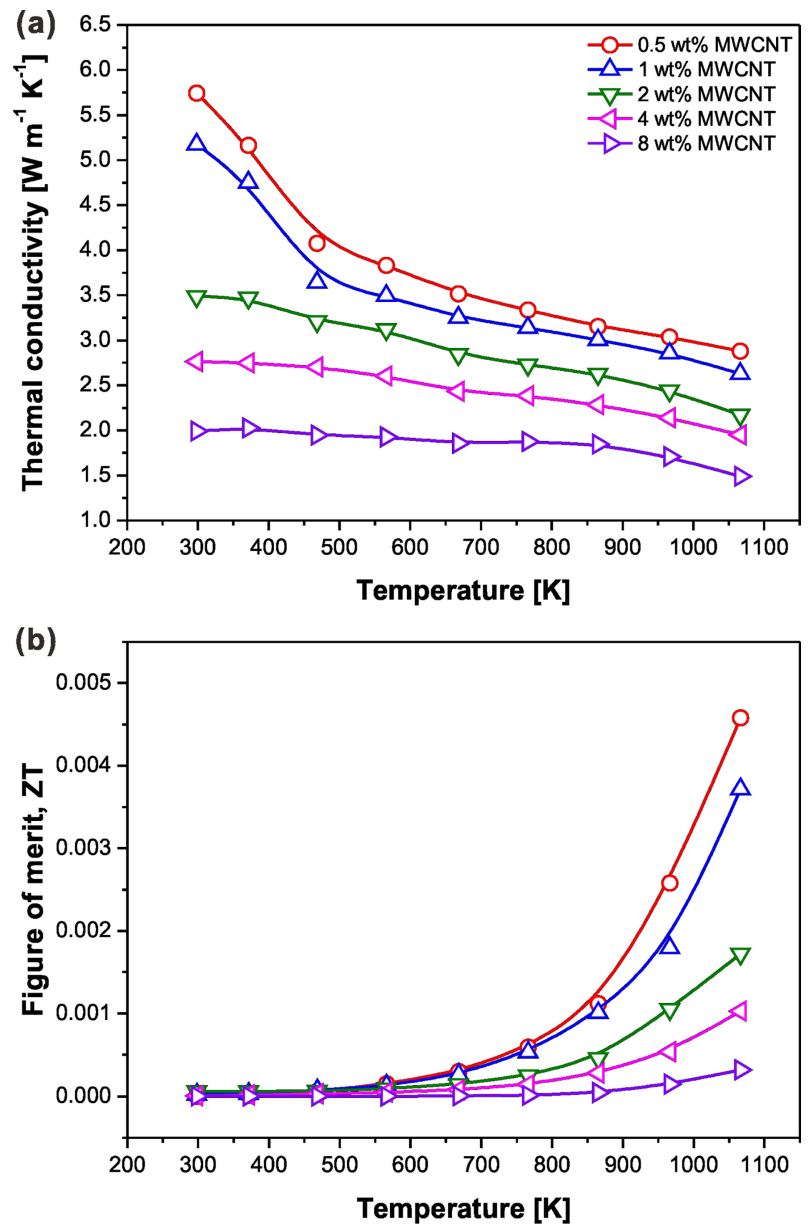

Fig. 6. Temperature dependent (a) thermal conductivities and (b) ZT values of $\mathrm{TiO}_{2}$-MWCNT nanocomposites.

그림 6(a)는 $\mathrm{TiO}_{2}-\mathrm{MWCNT}$ 나노복합체의 온도에 따른 열전도도의 변화를 나타낸다. 열전도도 $\left(\kappa_{\mathrm{tot}}\right)$ 는 전자에 의한 
기여분 $\left(\kappa_{\mathrm{el}}\right)$ 과 격자에 의한 기여분 $\left(\kappa_{\mathrm{lat}}\right)$ 의 합으로 나타내 며, 전자에 의한 열전도도는 Wiedemann-Franz 법칙에 의 하여 식 (2)와 같이 나타낸다.

$$
\kappa_{\mathrm{el}}=L \sigma T \text {, }
$$

여기서 $L$ 은 Lorenz number를 나타낸다. 이 관계를 통 해 전자에 의한 열전도도와 전기전도도는 서로 의존적인 관계를 가지게 되어 독립적인 제어가 쉽지 않지 않기 때문 에 열전성능지수 향상의 걸림돌이 되고 있다. 따라서 격자 열전도도를 제어함으로써 전체 열전도도를 낮추는 방향으 로 많은 연구가 이루어지고 있다. 그림 2에서 나타낸 것과 같이 $\mathrm{MWCNT}$ 함량이 증가함에 따라 전기전도도가 증가 함에도 불구하고 열전도도는 MWCNT 함량에 따라 지속 적으로 감소하는 경향을 보였다. 이러한 열전도도 저감 효 과는 나노복합체의 결정립계에 존재하는 MWCNT가 추가 적인 포논 산란 센터로 작용하여 격자 열전도도가 감소하 였기 때문이다. 결과적으로, MWCNT를 이용한 계면 제어 를 통해 나노복합체 내의 전자와 포논의 이동을 독립적으 로 제어할 수 있음을 증명하였다. 출력인자와 열전도도 특 성을 통하여 얻은 열전성능지수를 그림 6(b)에 나타내었 다. $\mathrm{TiO}_{2}-0.5 \mathrm{wt} \% \mathrm{MWCNT}$ 나노복합체에서 $1073 \mathrm{~K}$ 일 때 가장 높은 열전성능지수 $\left(Z T=4.6 \times 10^{-3}\right)$ 를 나타내었지 만, MWCNT 함량이 증가함에 따라 열전성능지수가 지속 적으로 감소하는 경향을 보였다.

\section{4. 결 론}

본 연구에서는 MWCNT를 이용한 계면 제어가 $\mathrm{TiO}_{2}$ 나노복합체의 열전특성에 미치는 영향에 대해 보고하였다. 미세구조 분석을 통하여 $\mathrm{MWCNT}$ 가 결정립계에 잘 분산 된 $\mathrm{TiO}_{2}-\mathrm{MWCNT}$ 나노복합체가 제작되었음을 확인하였 다. 계면 제어를 통해 나노복합체의 전기전도도의 상승과 열전도도의 감소 효과를 동시에 구현하는 것이 가능하다 는 것을 밝혀내었다, 하지만, $\mathrm{MWCNT}$ 함량이 증가함에 따라 급격한 제벡 계수의 감소로 인해 출력인자와 열전 성능지수는 MWCNT 함량에 따라 감소하는 경향을 나타 내었다. 결과적으로, $\mathrm{MWCNT}$ 가 $0.5 \mathrm{wt} \%$ 첨가된 나노복 합체에서 $1073 \mathrm{~K}$ 일 때 $4.6 \times 10^{-3}$ 의 가장 높은 열전성능 지수를 보였다. 본 연구 결과를 바탕으로 탄소나노물질을 이용해 계면이 제어된 열전소재가 폭넓게 활용되고 향후 보다 높은 열전성능지수를 구현하는데 도움이 될 것으로 기대한다.

\section{감사의 글}

본 연구는 한국연구재단 중견연구자지원사업 후속연구지 원(2018R1A2A2A05020902)을 통해 수행되었습니다.

\section{REFERENCES}

1. M. Grätzel, Inorg. Chem. 44, 6841 (2005).

2. A. J. Ragauskas, C. K. Williams, B. H. Davison, G. Britovsek, J. Cairney, C. A. Eckert, W. J. Frederick, J. P. Hallett, D. J. Leak, C. L. Liotta, J. R. Mielenz, R. Murphy, R. Templer, and T. Tschaplinski, Science 311, 484 (2006).

3. P. G. Bruce, B. Scrosati, and J.-M. Tarascon, Angew. Chem. Int. Ed. 47, 2930 (2008).

4. S. Chu and A. Majumdar, Nature 488, 294 (2012).

5. T. M. Tritt and M. A. Subramanian, MRS Bull. 31, 188 (2006).

6. G. J. Snyder and E. S. Toberer, Nat. Mater. 7, 105 (2008).

7. J. R. Sootsman, D. Y. Chung, and M. G. Kanatzidis, Angew. Chem. Int. Ed. 48, 8616 (2009).

8. P. Avouris, Z. Chen, and V. Perebeinos, Nat. Nanotechnol. 2, 605 (2007).

9. M. F. L. De Volder, S. H. Tawfick, R. H. Baughman, and A. J. Hart, Science 339, 535 (2013).

10. I.-J. Shon, Korean J. Met. Mater. 55, 110 (2017).

11. T.-K. Jung, M. Ryou, J.-W. Lee, S.-K. Hyun, H. G. Na, and C. Jin, Met. Mater. Int. 23, 1133 (2017).

12. J. Xu, L. Luo, G. Xiao, Z. Zhang, H. Lin, X. Wang, and J. Long, ACS Catal. 4, 3302 (2014).

13. B. H. Lee, J.-H. Lee, Y. H. Kahng, N. Kim, Y. J. Kim, J. Lee, T. Lee, and K. Lee, Adv. Funct. Mater. 24, 1847 (2014).

14. A. Pandikumar, G. T. Soon How, T. P. See, F. S. Omar, S. Jayabal, K. Z. Kamali, N. Yusoff, A. Jamil, R. Ramaraj, S. A. John, H. N. Lim, and N. M. Huang, RSC Adv. 4, 63296 (2014).

15. F. Gu, R. Nie, D. Han, and Z. Wang, Sens. Actuator B: Chem. 219, 94 (2015).

16. K. Turcheniuk, R. Boukherroub, and S. Szunerits, J. Mater. Chem. B 3, 4301 (2015).

17. Z.-S. Wu, G. Zhou, L.-C. Yin, W. Ren, F. Li, and H.-M. Cheng, Nano Energy 1, 107 (2012).

18. F. Bonaccorso, L. Colombo, G. Yu, M. Stoller, V. Tozzini, A. C. Ferrari, R. S. Ruoff, and V. Pellegrini, Science 347, 1246501 (2015).

19. L. Ji, P. Meduri, V. Agubra, X. Xiao, and M. Alcoutlabi, Adv. Energy Mater. 6, 1502159 (2016). 
20. W. H. Nam, B. B. Kim, S. G. Seo, Y. S. Lim, J.-Y. Kim, W.S. Seo, W. K. Choi, H.-H. Park, and J. Y. Lee, Nano Lett. 14, 5104 (2014).

21. W. H. Nam, B. B. Kim, Y. S. Lim, W.-S. Seo, H.-H. Park, and J. Y. Lee, J. Am. Ceram. Soc. 99, 2077 (2016).

22. W. H. Nam, Y. S. Lim, W. Kim, H. K. Seo, K. S. Dae, S. Lee, W.-S. Seo, and J. Y. Lee, Nanoscale 9, 7830 (2017).

23. W. H. Nam, B. B. Kim, Y. S. Lim, K. S. Dae, W.-S. Seo, H.H. Park, and J. Y. Lee, Nanoscale 9, 12941 (2017).

24. S. T. Lee and Y. S. Lim, Korean J. Met. Mater. 56, 163 (2018).

25. S. G. Seo, W. H. Nam, Y. S. Lim, W.-S. Seo, Y. S. Cho, and
J. Y. Lee, Carbon 67, 688 (2014).

26. W. H. Nam, Y. S. Lim, W. Kim, H. K. Seo, K. S. Dae, S. Lee, W.-S. Seo, and J. Y. Lee, Nanoscale 9, 7830 (2017).

27. Y. Fan, L. Wang, J. Li, J. Li, S. Sun, F. Chen, L. Chen, and W. Jiang, Carbon 48, 1743 (2010).

28. J. Foroughi, G. M. Spinks, S. R. Ghorbani, M. E. Kozlov, F. Safaei, G. Peleckis, G. G. Wallace, and R. H. Baughman, Nanoscale 4, 940 (2012).

29. G. A. Hope and A. J. Bard, J. Phys. Chem. 87, 1979 (1983).

30. F. Han, G. Meng, X. Zhao, Q. Xu, J. Liu, B. Chen, X. Zhu, and M. Kong, Mater. Lett. 63, 2249 (2009). 